"Mircea cel Batran" Naval Academy Scientific Bulletin, Volume XIX - 2016 - Issue 1

Published by "Mircea cel Batran" Naval Academy Press, Constanta, Romania // The journal is indexed in:

PROQUEST / DOAJ / DRJI / JOURNAL INDEX / I2OR / SCIENCE LIBRARY INDEX / Google Scholar / Crossref /

Academic Keys / ROAD Open Access / OAJI / Academic Resources / Scientific Indexing Services / SCIPIO

\title{
THE SEAFARERS' HUMAN CAPITAL VARIABLES AND THE CREW PROFILE DYNAMIC ADJUSTMENT
}

\author{
Catalin POPA ${ }^{1}$ \\ Filip NISTOR ${ }^{2}$ \\ Imre RECZEY ${ }^{3}$ \\ David QUANSAH ${ }^{4}$ \\ ${ }^{1}$ Business Faculty, Higher Colleges of Technology, United Arab Emirates \\ ${ }^{2}$ Senior Lecturer, PhD, Faculty for Navigation and Naval Management, Mircea cel Batran Naval Academy, \\ Constanta, Romania \\ ${ }^{3}$ Head of Business Department, PhD, ADMC-Higher Colleges of Technology, United Arab Emirates \\ ${ }^{4} \mathrm{PhD}$ student at British University in Dubai, Dubai, United Arab Emirates
}

\begin{abstract}
The human capital is one of the most relevant functional dimensions of the maritime transportation business, considering the seaborne particularities in the crossing countries, cultures and heterogeneous environment as onboard the maritime vessels. The nowadays great competitiveness in this area of transportation services has encouraged many companies to pursue new ways to maintain a competitive advantage, valuing its human capital. Thus, in spite of the propensity for standardisation in field of human resources profile, the seafaring crews' management is still facing lots of issues in operational tasks' fulfilment onboard to maritime ships, due to individual misalignment within the collective framework of the on-board teams. As is presented in the article, the individual profile of a seafarer has to be precisely defined to be efficiently integrated in the crew, but not only in professional matters, but also into a comprehensive manner, in order to support a proper adjustment of the individual seafarer behaviour to the group profile requirement, onboard to maritime vessels. STCW provisions are very welcomed in establishing common standards for professional variable of the seafarers' individual profile, but is still missing to approach the organizational dimensions, apart to the leadership skills or risk behaviour. As shown in the article below, for a recruitment agent and further, for the ship Master is important to find the suitable employee, not only in terms of professional knowledge, skills and abilities, but also in cultural or psychosociological individual dimensions, as to adjust the individual to the group profile, accordingly and effectively.
\end{abstract}

Keywords: Maritime transport, shipping, crew management, maritime human resources, HR profile

\section{Introduction in Maritime Human Resources (MHR) theory}

The Human Capital $(\mathrm{HC})$ is one of the most relevant dimensions of the maritime transportation businesses, considering the work placement environment heterogeneity, as on board the ships. The Maritime Human Resources (MHR) comprises as wider conceptual perspective, the multidimensional sum of those processes occurred within organisational chart design and implementation policies and strategies, framing the processes related to the recruitment, selection, employment, crewing, onboard deployment, training and adjustment, usage/performance and assessment of manpower on board the commercial vessels or in relation with the seaborne operations.

In spite of international endeavours for standardisation of MHR processes, seeking to bind both individual profile features and the crew integrative profile, the seaborne crew management is still facing lots of issues in operational tasks' fulfilment onboard the maritime ships, due to individual misalignment within the operational framework on-board the ships. These

DOI: 10.21279/1454-864X-16-I1-016

(C) 2015. This work is licensed under the Creative Commons Attribution-Noncommercial-Share Alike 4.0 License. unconformities transformed in incidents use to significantly affect the ship efficiency and effectiveness in operation, being determined by to the heterogeneous frame of professional, psychosocial, cultural and communication mixture of individual characteristics in such crews. Considering these particularities, as further presented in the article, the individual profile of the seafarers should to be accurately defined in order to achieve an efficiently collective integration of individuals within the onboard functional crew.

Thus, this integration should regard not only the professional perspective, but it has to use a comprehensive defining manner, to support a proper adjustment an individual seafaring behaviour to the group profile requirement, to perform onboard the maritime vessels, in fully respect of SOLAS standards, regarding the life and goods' safety. STCW provisions is welcomed in establishing common standards for professional variables of the seafarers' individual profile, but is still missing to approach the organizational dimensions, apart to leadership skills or risk behaviour. Moreover, as shown in the article, for the crewing (manning) agency and further, for the 


\begin{abstract}
"Mircea cel Batran" Naval Academy Scientific Bulletin, Volume XIX - 2016 - Issue 1
Published by "Mircea cel Batran" Naval Academy Press, Constanta, Romania /I The journal is indexed in: PROQUEST / DOAJ / DRJI / JOURNAL INDEX / I2OR / SCIENCE LIBRARY INDEX / Google Scholar / Crossref /

Academic Keys / ROAD Open Access / OAJI / Academic Resources / Scientific Indexing Services / SCIPIO
\end{abstract}

ship Master is important to find the suitable employee, not only in terms of professional knowledge, skills and abilities, but also in cultural or regarding the psycho-sociological individual dimensions, to adjust accordingly the individual performance to the group objectives and operational tasking framework. Calling for the human capital basics, as a major component of MHR, the seafarers' adjustment programs have to achieve not only the professional requirements fulfilment but also to solve the major nonconformities of the individuals in relation with a predefined crew profile onboard the ships, in order to integrate the seafarer in the team from all standpoints inter and intra group featuring.

\section{Research Methodology}

This study will apply an conceptual and interpretative approach on a modelling basis, valuing the literature review findings in this respect (Hackley, 2003). As qualitative research tool, the modelling techniques will be used to build a comprehensive model for the individual profile in relation with the team goals and operational framework within onboard crew management, as to be further empirically tested. Therefore, the study starts as a theoretical onset for further empirical tests, in order to validate the model and to quantify the real proportions of the theoretical variables.

Therefore, the qualitative technique has been used to design a comprehensive human profile matrix, to reveal the major components of the $\mathrm{MRH}$, in relation with the international standards as enforced by STCW. There were reflected, in a systemic view, the maritime human resources variables in recruitment, selection and employment processes, but under static perspective, underpinning the major components of the individual and organizational profiles for a shipping company. This matrix should be further useful to determine and to analyze the relations between individual manpower variables and the crew management objectives, comprising all theories of international human resources together (figure no. 1). Following the qualitative methodology of modelling, the authors have further designed the dynamic profile of the seafarers, on the same systemic perspective, but considering the crew onboard the vessel as a sum of all individual knowledge and competencies, hereby seeking to reveal the multi-criteria relations between the group profile and the individual variables within the onboard framework (figure no. 2).

The qualitative technique has been also interpreted a wide literature review, about seafarers' selection, recruitment adjustment processes and practices. The study underwent $a$ scientific approach using an extensive literature review and further developing a conceptual framework that can be useful to identify those variables within Maritime Human Resources matrix (Maylor and Blackman, 2005, p.143). As result a ground basis will be settled, for the future studies in quantitative perspective, to quantify the individual adjustment of a seafarer onboard the ships' crew, by collecting data from different entities and interviewed professionals. Each profile variable should be further quantified based on multi-criteria analysis, in relation with the determined ship crew profile, becoming a powerful tool for onboard management and for increasing the human resources performance in maritime business area.

Maritime Human Resources (MHR) analysis in relation with expatriates' theories

The Maritime Human Resources (MHR) comprises as wider conceptual perspective, the multidimensional sum of those processes occurred within organisational chart and the implementation policies and strategies, framing those processes of recruitment, selection, employment, crewing, onboard deployment, training and adjustment, usage/performance and assessment of manpower on board the commercial vessels or in relation with other seaborne operations. In this case, the seafarers should be assimilated, due to their work conditions, as having an expatriate status. The onboard work tasks as undertaken within international environment, embedded with intercultural interactions and the employment opportunity is usually accepted voluntarily.

The seafarer is acting as an expatriate, screening the market job himself or contacting a crewing company for these purposes. Therefore, if is the case to analyse the MHR processes'performance we should seek first for major theories of expatriates to shed the light over the major particularities of seafarers as international human capital itself.

In this order the selection process should attribute varying levels of importance to the factors that contribute to success or failure on the job, even onboard the maritime vessels. The practical approaches for selection process should be contingent on the nature of the job, the personality characteristics of the seafarer candidate, and the culture of the vessel identity, if the case for a national flag. But in case of the ships registered in a foreign open registry, under a convenience flag, the approach is more complicated. Having a multicultural crew with a diluted national identity, the crew profile will more difficult to be described and designed. 


\begin{abstract}
"Mircea cel Batran" Naval Academy Scientific Bulletin, Volume XIX - 2016 - Issue 1
Published by "Mircea cel Batran" Naval Academy Press, Constanta, Romania /I The journal is indexed in: PROQUEST / DOAJ / DRJI / JOURNAL INDEX / I2OR / SCIENCE LIBRARY INDEX / Google Scholar / Crossref /

Academic Keys / ROAD Open Access / OAJI / Academic Resources / Scientific Indexing Services / SCIPIO
\end{abstract}

Older studies have initially revealed that inability of employees to adjust to the new environment, family related issues, personality or emotional immaturity, or inability to cope with responsibilities associated with the new job represent the main reasons for expatriates' failure (Tung, 1987). This matter becomes more relevant in shipping, where most of the companies, due to STCW requirement, use to overemphasize the technical competences, skills and abilities, neglecting other significant employee characteristics such as relational abilities, communication skills, multicultural awareness and flexibility and so on. Other authors have further asserted that the recruitment and selection processes as being culturally sensitive, as empathic indicator for the crew, in terms of employee's willingness to accept the intercultural challenges, being culturally prepared for the job (Yavas, Bodur, 1999). In case of onboard jobs, for both officers and ratings, the cultural awareness and ability to adapt and to adjust the individual behaviour within a crew predefined profile on limited voyage time is obviously very relevant; these abilities should be priory identified in the selection and recruitment stage, but depending on the crew profile defined temporarily, at the spot, for a limited span time as in the contract.

Several researchers attributed a more relevant importance for the selection process, arguing that including key determinants in the selection process would result in more effective expatriate managers (Mendenhall and Oddou, 1987; Tung 1981). When the ship is under a national flag then the host country cultural particularities should prevail when select the manpower for a specific voyage - then the management should look for a precise profile defined by professional and cultural standards, in a precise framework. But nowadays, careful consideration should be given to the onboard crew profile, in terms of intercultural issues, when flag of convenience is used and the staffing services are aiming the international market of seafarers, as in most of the cases. So, the management should be able to define first a dynamic profile for the crew on temporary basis and depending on this variables to develop a proper selection process for individuals as to fit and adjust the short term contractual manpower within the collective framework onboard the ship. Some authors have proposed a multifaceted approach to the selection of expatriate employees, an approach that links behavioural tendencies to the expected overseas performance (Mendenhall and Oddou,1985). Even more, according to other researchers, the expatriates "are more likely to be attracted to, selected by, perform better in, and remain in organizations that are compatible with their personal characteristics" (Oh et al, 2014, p.2). For seafarers will be very difficult to adjust to the new environment for at least two reasons: 1) the environment is dynamic, changing the variables together with the crew member, on permanent basis; 2) the contract is usually up to maximum six months that makes difficult any further adjustment for a long term. In this context, the seafarers should identify themselves with a maritime culture that should be defined more on common working principles on board the ship and less in the cultural side of a particular nationality, as the flag is of convenience.

In conclusion to the literature review in the similar area of expatriates' selection process theory, becomes clear that developing a profile for a seafarer temporary embarked onboard the ship will serve as an essential element in designing and implementation of proper selection and training HR programmes for the commercial fleet, in order to assure an optimum adjustment of such dynamic crew. Employers will always seek to select officers and ratings who will meet the technical standards of the job, with higher adaptive skills within a continuous changing environment, and with a loyal attitude regarding the organization values and norms. On the other hand, potential employees would like to work for an organization that would use their abilities and meet their particular needs, on a long term basis. Therefore, for an efficient recruitment process is very important to develop a crewing model that combines the characteristics of a potential seafarer with the organizational environment variables, as to fulfil all the requirements not only in professional matters, but in behaviour and cultural dimensional as well.

The seafarer profile definition - static and dynamic profile determinants

In order to define and to shape the contemporary model for seafarers' profile, the most visible theories for expatriates have been considered together and adapted for maritime industry. The theories were considered together with the STCW requirements and professional standards, valuing the literature conclusions regarding the organizational dimensions, as outlined by Tung (1981a), Black, Mendenhall and Oddou (1991), Shaffer et al (1999), and Mendenhall and Oddou (1985) (figure no. 1).

In this respect, valuing the most known literature variables, the expatriate seafarers' profile has been priory shaped as having four classical distinctive and interdependent dimensions, namely: professional profile, organisation-specific requirements, individual personality profile, and social \& intercultural variables. These four 
"Mircea cel Batran" Naval Academy Scientific Bulletin, Volume XIX - 2016 - Issue 1

Published by "Mircea cel Batran" Naval Academy Press, Constanta, Romania // The journal is indexed in: PROQUEST / DOAJ / DRJI / JOURNAL INDEX / I2OR / SCIENCE LIBRARY INDEX / Google Scholar / Crossref /

Academic Keys / ROAD Open Access / OAJI / Academic Resources / Scientific Indexing Services / SCIPIO

dimensions were compound together on an profile matrix, as basic determinants of the seafarers' static perspective MHR profile (figure no. 1). This perspective is focused on the conformity and compliance of the employee with the onboard rules and with the organizational culture. In this case, the profile is assessed based on those features assumed through internal environment variables, the employee being in the position to adjust his behaviour within predicted parameters. This is a sort of static organizational profile, mainly oriented toward effectiveness, efficiency and economic performance. The seafarers' behaviour onboard will be explained by a dynamic perspective as a complex sum of all employees' behaviour, counting all crew integrative dimensions from the HRM profile matrix drawn below (see figure no. 2).

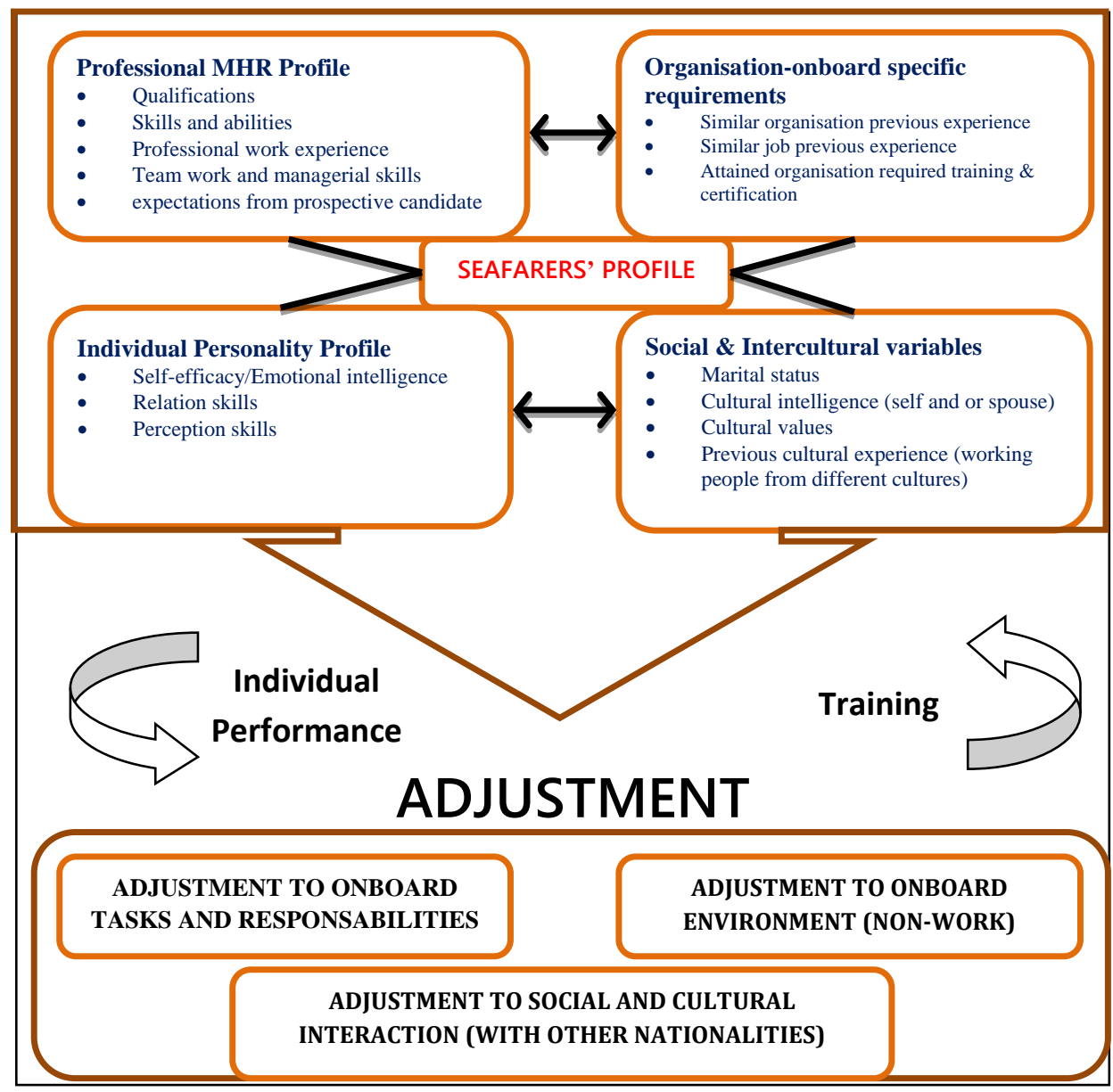

Figure no. 1 The Maritime Human Resources static profile determinants (Adapted by authors in synthesis of the literature review)

\section{MHR Professional profile}

This dimension of professional profile seeks for seafarers' qualifications, skills, abilities, work experience, managerial skills, cumulating the professional performance expectations from a prospective candidate, all of which should be aligned with the organisation's needs and onboard assignments. In theory, individual job performance is a function of knowledge, skills, abilities, and motivation defined by a role prescribed behaviour, such as formal job responsibilities. Apart to these factors there were introduced another two moderating variables for a professional profile that suits the seafarers as well: previous assignments portfolio (as experience support) and language fluency (as communication effectiveness factor), often used as selection criterion (Black et al, 1991; Shaffer et al, 1999). Since organisational culture might be different one organisation to another, this means that seafarers should possess the right knowledge, skills and abilities (KSA's) that match the requirements of the organisation, being able to fit accordingly in the predicted standards. If the seafarers KSAs are matching STCW requirement, then is more likely to have a smooth transition onboard, the sailor 


\begin{abstract}
"Mircea cel Batran" Naval Academy Scientific Bulletin, Volume XIX - 2016 - Issue 1
Published by "Mircea cel Batran" Naval Academy Press, Constanta, Romania /I The journal is indexed in: PROQUEST / DOAJ / DRJI / JOURNAL INDEX / I2OR / SCIENCE LIBRARY INDEX / Google Scholar / Crossref /

Academic Keys / ROAD Open Access / OAJI / Academic Resources / Scientific Indexing Services / SCIPIO
\end{abstract}

performing efficiently the new job tasks, at "full" capacity. Since the onboard positions are standardized now is considered then the seafarers will not be treated as newcomers in terms of professional requirement, the major differences or non-conformities in performance coming mainly from behaviour, social and crosscultural dimensions.

\section{MHR Organisational - onboard specific dimension}

This variable is connected to the professional dimension, completing the professional profile frame. As previously indicated, organisational culture and previous experience of the sailor might differ from company to company this means that employees should possess the right certifications that match the STCW requirements, as updated in last Manila agreement.

In some cases the organisation might require the employee to have attained specific qualifications that might only be specific to the particular ship or type of transportation (as dangerous goods) and probably not required by other type of maritime company in the industry. This dimension refers to the company requirements imposed by international agreements (e.g. SOLAS convention with its annexes or STCW) or by different regulatory authorities in the flag countries or in route port calling destinations.

The professional and organizational dimensions are the most relevant pillars on sight for defining and assessing the seafarer's professional profile in ship manpower, any of these standards being a prior condition to be fulfilled or further acquired by specific training programs. The adjustment program should include first these professional and organizational requirements (figure no. 1).

\section{MHR individual personality profile}

But for completing the profile frame, the employee should be analysed through its individual identity dimensions, as defined by the personality or by social and inter-cultural interactions. The identified individual personal traits or relational abilities are one of those consistent variables that contribute to success or failure on the job appointment and, therefore should be used to guide the crewing process in the selection stage. This variable is not limited to a simple knowledge of another culture features, but include also the ability to live and work with people whose axiological systems, beliefs, customs, manners and ways of conducting businesses may greatly differ from one's own (Tung, 1981a). In this respect, some authors found that extraversion, emotional stability, and openness to change had a significant, positive impact on seafarer adjustment, while agreeableness positively influences the job performance (Downes et al, 2010). As other scholars have indicated, all personality features, apart from conscientiousness, can bring a significant influence on seafarers' effectiveness and success, considering that the sailors who are emotionally stable, who are outgoing and agreeable, and who are high in openness to experience seem to function better than others (Shaffer et al, 1999, p. 122). Hence, the crew members who possess the appropriate personality features for a given onboard role in a given environment will perform better in their duties, compared with those who do not possess the appropriate personality characteristics for that same assignment (Caligiuri et al, 2001).

In a broad view can be concluded that the personality variables can be considered a valid predictor of seafarer job performance, valuing individual different variables related to expatriate job performance such as: personality trait, selfefficacy, motivation, communicational ability, stress tolerance, relational ability, and prior international experience (Shaffer et al, 1999). Personality itself has been defined as enduring emotional, interpersonal, experiential, attitudinal and motivational style that explains individual's behaviour in different situations (McCrae, Costa, 1989).

Looking further should be found that some attributes such as self-efficacy, relation skills, perception skills, emotional intelligence, can be also considered vital to the effective performance of an embarked officer or rating, other variables as self-dimension, the relationship dimension, and the perception dimension being essential for seafarers success (Black et al, 1991). These requirements were based, as the initial research stated, on the "self- efficacy" centres of skills that an onboard manpower needs to have in order to be self-effective in relation with the stress management and psychological well-being (Mendenhall et al, 1985). The individuals who are more flexible in learning new behaviours will get on higher self-efficacy levels, proving themselves more likely to adjust faster and more efficient in a new environment since they are prepared and wishful to try and learn new behaviours even for a short time as in the maritime crew case (Black et al, 1992; Feitosa et al, 2001).

The relational skills are very relevant component of this dimension involving a wide range of expertise that can facilitate "easy" interaction, this attribute referring to the "interaction adjustment facet" about how the individual relates in another hosting environment. In this regard, possessing relational skills can decrease the uncertainty related to an unfamiliar environment. A seafarer 


\begin{abstract}
"Mircea cel Batran" Naval Academy Scientific Bulletin, Volume XIX - 2016 - Issue 1
Published by "Mircea cel Batran" Naval Academy Press, Constanta, Romania /I The journal is indexed in: PROQUEST / DOAJ / DRJI / JOURNAL INDEX / I2OR / SCIENCE LIBRARY INDEX / Google Scholar / Crossref /

Academic Keys / ROAD Open Access / OAJI / Academic Resources / Scientific Indexing Services / SCIPIO
\end{abstract}

should find it easier to understand a foreign culture and to interpret properly the onboard maritime environment variables when he possess greater perception skills, being able to adopt an appropriate behaviour in the new frame of work.

MHR social and intercultural dimension

This final dimension completes the seafarers' individual identity analysis, being useful to detail the employee's ability to identify and to cope with the environmental structures and constraints, such as institutional structures, unions, crew members, as an important prior work hypothesis toward effectiveness and efficiency. This dimension is very relevant to the individual adapting skill since the environment onboard the maritime vessels, including for national or convenience flag, may be consistently vary one to another, and far away from the environment which the sailor is familiar with.

A recent study has revealed that socio-cultural similarities would facilitate general environmental fitting of a person and a smoother living adjustment of expatriates, once they are able to understand the systems' variables and how to operate with it (Koveshnikov et al, 2014). In case of sailors these adjustments should be done periodically, in accordance with a crew profile at the moment. The individuals should be warned about the crew profile, as relevant to the cultural dimension. For a short term deployed onboard, the seafarer should fit and act as a team member within a very heterogeneous social and cultural environment, being kept to understand, accept and value the cultural variables when the case. Their adjustment onboard is essential for the daily equilibrium in daily life, as in professional daily routines, affecting very consistent the performance and the personal attitudes on a short and medium range.

The Maritime Human Resources dynamic profile determinants

The seafarer profile matrix can be represented like in the figure no. 1 outlines in order to describe on common basis the most important determinants that should be considered on a static perspective of the MHR adjustment processes. In this matrix the major profile components should be subordinated to the crew adjustment processes, comprising the individual adapting variables onboard, against the work environment, non-work environment and the interactive environment. But in MHR management is important not only the individual dimensions in ratio with a predefined set of requirements or appointed standards. The crew is always changing and the seafarer is forced to adapt himself to a changing group profile, to perform efficient in the voyage time.
So, in figure no. 2, the initial matrix has been enriched, from a simple depiction of a seafarer profile adjustment to the environment, to a crew integrative approach, segregated in seafarers' individual human identity (appealing the individual personality and social and intercultural profiles) and the seafarers' individual professional profile (technical and non-technical requirements). Therefore, in the designed model three steps will be identified:

a) Seafarer Individual Profile Definition - by this component the seafarer is self defined dynamically, counting progressively the "visible" technical and non-technical requirement, in terms of fulfilling the required organizational expertise, knowledge or, cultural/social competencies, in compliance with STCW or other IMO standards. With this profile the seafarer will advance an individual potential offer in recruitment and selection processes - that can be proved and tested based on traditional methods.

b) Onboard Crew Profile Definition - the company is stating its requirements standards and rules, interacting with the individual profiles, overtaking the selection, recruitment and employment processes, but usually having information mostly from the seafarer individual profile, defined by technical and non-technical KSA's. But the crew is more complicated and dynamically defined, changing often its structure and components. The company should try to identify together with the selection process also the crew profile in terms of socio and cultural profile. The seafarer, based on its individual behaviour and cultural variables will interact and suit or not in the crew. Here is not only about the technical and non-technical requirements as in STCW. But is more about "non-tangible" qualities and individual performing variables as behaviour skills (e.g. leadership, team working, communication, assertiveness skills) or as cultural variables. Further the cultural profile is difficult to be evaluated before embarking the seafarer onboard, within a crew, being about blaming culture (rules perception) or just culture indicators (perceptions, traditions, social skills etc.). The cultural profile should rely on cultural intelligence and previous cultural experiences as variables to be evaluated by the recruiter based on specific tests, or developing a dynamic vitae for these purposes. For the Ships' Master or for other managers onshore, is important to know what kind a seafarer do they need in their crew at the moment, depending not only on the STCW requirements, but also on the crew dynamic profile, as to integrate properly the individual within the group, in professional, social and cultural dimensions. 
"Mircea cel Batran" Naval Academy Scientific Bulletin, Volume XIX - 2016 - Issue 1

Published by "Mircea cel Batran" Naval Academy Press, Constanta, Romania // The journal is indexed in: PROQUEST / DOAJ / DRJI / JOURNAL INDEX / I2OR / SCIENCE LIBRARY INDEX / Google Scholar / Crossref /

Academic Keys I ROAD Open Access / OAJI / Academic Resources / Scientific Indexing Services / SCIPIO

c) Maritime Human Capital Value - is the last stage that comes as result of previous two profiles' interaction, when the individual seafarer fits in the crew. The human capital value is a result of featuring both STCW requirements and onboard rules individual compliance with a successful individual interaction onboard as a crew member, contributing to the maritime voyage performance.

The concept of developing an seafarer profile is based on expatriate profile components' depiction starting from the concept of "person $\leftrightarrow$ environment" adjustment $(P-E)$, defined as an interactive ratio based on the degree of compatibility or match between individuals and some aspect of their work environment. This concept of employee compatibility is outlined in a vivid perspective considering that behaviour $(B)$ is a function of the person (P) and his/her environment $(E)$, where $B=f(P, E)$ (Oh et al, 2014 , p.2). This equation underpins that seafarers' personal characteristics and crew onboard variables are the two major forces that will interact to shape the individual behaviour onboard to maritime vessels. Accordingly, individuals will seek to achieve and to preserve the full compliance with their environmental variables, looking for positive workplace relationships and further for a career successful path.

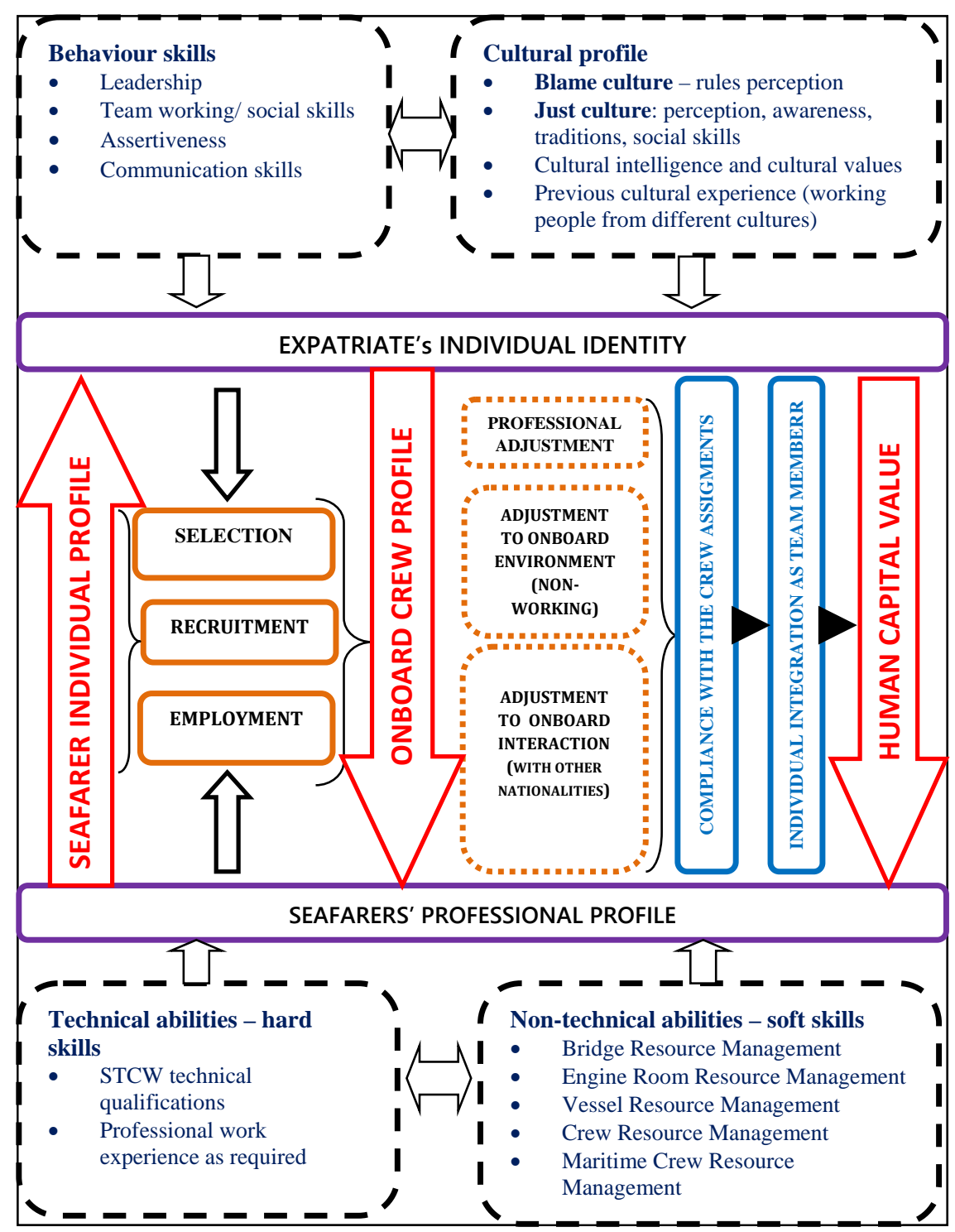

Figure no. 2 The Maritime Human Resources dynamic profile determinants 


\begin{abstract}
"Mircea cel Batran" Naval Academy Scientific Bulletin, Volume XIX - 2016 - Issue 1
Published by "Mircea cel Batran" Naval Academy Press, Constanta, Romania /I The journal is indexed in: PROQUEST / DOAJ / DRJI / JOURNAL INDEX / I2OR / SCIENCE LIBRARY INDEX / Google Scholar / Crossref /

Academic Keys / ROAD Open Access / OAJI / Academic Resources / Scientific Indexing Services / SCIPIO

\section{CONCLUSION}

As resulted from the literature review endeavour, the Maritime Human Resources are a particular dimension of international HR and has to be treated and recognized as one of the most dynamic and interactive area of study within this body of knowledge. Comparing with classic expatriate theories, the MHR is embedded by two major particularities that change the rules and make it more unpredictable: 1 ) the crew is changing on a short run, presenting a dynamic profile; 2) the seafarers are defined initially based on STCW requirements but will further perform within a dynamic group, forced to ongoing fit within a changing environment on a short run.

Thus, the selection and recruitment processes should be improved to overcome all the performing impediments, seeking to support the individual fitting impact within onboard crew. The seafarers' profile has to be completed with other evaluation methods to reveal the integrative variables in the dynamic crew. First, the present research has synthesized the major concepts in maritime international human resources definition, depicting the major descriptor of seafarers profile, under the matrix of a static perspective of seafarers' profile determinants (figure no. 1). Secondly, once the profile features were revealed, the study has been enlarged in order to update the contemporary relation between seafarers and the onboard crew variables in relation with the organizational environment, under the matrix of matrix of a static perspective of seafarers' profile determinants (figure no. 2). The differences between those two perspectives are related to the new considerations about the seafarers' selection, recruitment and onboard adjustment processes. Therefore, synthetically:

- the static model is described by the next equation: "STCW requirements $\rightarrow$ seafarers' profile $\rightarrow$ rules compliance $\rightarrow$ individual performance" - traditional perspective that shapes the seafarers' profile based on compliance and adjustments;

- the dynamic model is described by the next equation: "dynamic crew profile $\rightarrow$ seafarers' profile $\rightarrow$ adjustment and compliance $\rightarrow$ integrative performance" - modern perspective considering both rules compliance and behaviour and cultural variables.

\title{
BIBLIOGRAPHY
}

[1]. Black, J., Mendenhall, M. (1990). Cross-Cultural Training Effectiveness: A review and a Theoretical Framework for Future Research. Academy of Management Review, 15(1), 113-136.

[2]. Black, J. S., Gregersen, H. B. (1991). Antecedents to Cross-cultural Adjustment for Expatriates in Pacific Rim Assignments. Human Relations, 44(5), pp 497-515.

[3]. Black, J.S., Gregersen, H.B., Mendenhall, M. (1992). Global Assignments: Successfully Expatriating and Repatriating International Managers, Jossey-Bass, San Francisco, CA.

[4]. Caligiuri, P., Phillips, J., Lazarova, M., Tarique, I., Burgi, P. (2001). The theory of met expectations applied to expatriate adjustment: the role of cross-cultural training. International Journal of Human Resource Management,12(3), 357-372.

[5]. Coyle John, et.al. Transportation. A Supply Chain Perspective, 2nd edition. Publishing House: South Western Cengage Learning, Mason, 2011.

[6]. Dessler, G. (2009). A Framework for Human Resource Management (5 ${ }^{\text {th }}$ edition). Pearson Prentice Hall, Pearson Education International, London.

[7]. Downes, M., Varner, I. I., Hemmasi, M. (2010). Individual profiles as predictors of expatriate effectiveness. Competitiveness Review: An International Business Journal, 20(3), 235-247.

[8]. Feitosa J., Kreutzer C., Kramperth A., Kramer W.S., Salas E., (2014). Expatriate Adjustment: Considerations for Selection and Training, Journal of Global Mobility: The Home of Expatriate Management Research, Vol. 2 Issue: 2.

[9]. Gordon, G. G. (1991). Industry determinants of organizational culture. Academy of Management Review, 16(2), 396-415.

[10]. Hackley, C. (2003). Doing Research Projects in Marketing, Management and Consumer Research, Routledge: London.

[11]. Koveshnikov, A., Wechtler, H., \& Dejoux, C. (2014). Cross-cultural adjustment of expatriates: The role of emotional intelligence and gender. Journal of World Business, 49(3), 362-371.

[12]. Leibra-O'Sullivan, S. (1999). The distinction between stable and dynamic cross-cultural competencies: Implications for expatriate trainability, Journal of International Business Studies, Vol. 30, No. 4, 709- 725 .

[13]. Lundy O., Cowling A. (1996). Strategic human resource management, Routledge, London.

[14]. Marcoulides, G. A., Heck, R. H., Papanastasiou, C. (2005). Student perceptions of school culture and achievement: testing the invariance of a model. International Journal of Educational Management, 19(2), 140-152. 
"Mircea cel Batran" Naval Academy Scientific Bulletin, Volume XIX - 2016 - Issue 1 Published by "Mircea cel Batran" Naval Academy Press, Constanta, Romania // The journal is indexed in: PROQUEST / DOAJ / DRJI / JOURNAL INDEX / I2OR / SCIENCE LIBRARY INDEX / Google Scholar / Crossref / Academic Keys / ROAD Open Access / OAJI / Academic Resources / Scientific Indexing Services / SCIPIO

[15]. Maylor, H., Blackmon, K. (2005). Researching Business and Management, Palgrave Macmillan: Houndmills, Basingstoke.

[16]. McCrae, R. R., Costa, P. T. (1989). The structure of interpersonal traits: Wiggins's circumplex and the five-factor model. Journal of personality and social psychology, 56(4), 586.

[17]. Mendenhall, M. E., and G. Oddou. (1985). The Dimensions of Expatriate Acculturation: A Review. Academy of Management Review, 39-47.

[18]. Muller, R., Turner, R. (2009). Leadership competency profiles of successful project managers. International Journal of Project Management 28 (2010) 437-448. Elsevier Ltd. France.

[19]. Oh, I. S., Guay, R. P., Kim, K., Harold, C. M., Lee, J. H., Heo, C. G., \& Shin, K. H. (2014). Fit Happens Globally: A Meta-Analytic Comparison of the Relationships of Person-Environment Fit Dimensions with Work Attitudes and Performance Across East Asia, Europe, and North America. Personnel Psychology, 67(1), 99-152.

[20]. Pettigrew, A. M. (1979). On studying organizational cultures. Administrative science quarterly, 570581.

[21]. Richardson, J., McKenna, S. (2002). Leaving and experiencing: why academics expatriate and how they experience expatriation. Career Development International, 7(2), 67-78.

[22]. Schein, E. H. (2004). Organisational culture and leadership 3rd ed., Jossey-Bass, San Francisco.

[23]. Scott, P. (1994). Wider or deeper? International dimensions of mass higher education, Journal of Tertiary Education Administration, Vol. 16 No. 2, pp.179-94

[24]. Shaffer, M.A., Harrison, D.A. (1999). Expatriates' Psychological Withdrawal from International Assignment: Work, Nonwork, and Family Influences. Personnel Psychology, 51, pp 87-118.

[25]. International Maritime Organization, (2010). Convention on Training, Certification and Watchkeeping for Seafarers, STCW, IMO, London.

[26]. International Transport Workers' Federation, ITF (2013), STCW Guide for seafarers taking into account the Manila Amendments, ITF, London

[27]. Stopford, M. (2009). Maritime Economics. $3^{\text {rd }}$ Edition, Routledge, London.

[28]. Tung, R L (1981a). Selection and training of personnel for overseas assignments. Columbia Journal of World Business, 16, 68-78.

[29]. Tung, R. L. (1981b). The new expatriates: Managing human resources abroad. Academy of Management Executive, 1(2):110-120.

[30]. Tung, R.L. (1987). Expatriates assignments: enhancing success, minimizing failures. Academy of Management Executive, 1(2):117-126.

[31]. Yadav, V. (2014) Learning in a Global Cross-Cultural Work Environment-The Expatriate Experience. Journal of Business \& Economic Policy, 1(2), 70-78.

[32]. Yavas, U., Bodur, M. (1999). Correlates of Adjustment: A Study of Expatriate Managers in an Emerging Country. Management Decision, 37 (3): 267-278. 